\title{
ANALISIS PEMANGKU KEPENTINGAN (STAKE HOLDER) WADUK SEMPOR DALAM PENGELOLAAN SUMBERDAYA PERAIRAN YANG BERKELANJUTAN
}

\author{
Fuquh Rahmat Shaleh*
}

\author{
Fakultas Perikanan Universitas Islam Lamongan \\ Jl. Veteran no. 53A Lamongan Phone/Fax.0322_324706
}

\begin{abstract}
ABSTRAK
Pengelolaan suatu sumberdaya perairan sangat di tentukan oleh peran pemangku kepentingan (Stake holder). Waduk Sempor merupakan salah satu waduk yang memiliki beberapa fungsi dalam pengelolaannya. Oleh karena itu identifikasi peran pemangku kepentingan (stake holder) di Waduk Sempor perlu diketahui guna terciptanya pengelolaan sumber daya perairan yang berkelanjutan. Penelitian ini bertujuan untuk menganalisis pemangku kepentingan (stakeholder) dalam pengelolaan perairan di Waduk Sempor yang dilaksanakan pada Januari-April 2014. Metode yang digunakan adalah metode deskriptif secara logik dengan analisis stakeholder. Pemangku kepentingan (stakeholder) di Waduk Sempor terbagi dalam tiga bidang yaitu perikanan, wisata dan PLTA serta Irigasi. Stakeholder di bidang perikanan yang berpengaruh besar dan sangat penting antara lain, Dinas Perikanan, Kelompok Nelayan, Kelompok KJA serta Petani KJA. Stakeholder di bidang wisata yang berpengaruh besar besar dan sangat penting yaitu Kelompok Perahu Wisata serta pedagang sedangkan Dinas Pariwisatanya tidak berpengaruh pada pengembangan. Balai Besar Wilayah Sungai Serayu Opak (BBWSSO) merupakan satu-satunya stakeholder yang berpengaruh besar dan penting di Bidang PLTA dan irigasi. Perlunya kesepakatan bersama seluruh stakeholder dalam penentuan Prinsip batas yurisdiksi (juridictional boundaries); Hak kepemilikan (Property right); dan Aturan keterwakilan (Rule of Representative) di Waduk Sempor.
\end{abstract}

Key words : Stakeholder, pengelolaan berkelanjutan, Waduk Sempor

\section{PENDAHULUAN}

Kementrian PPN/ Bapenas (2014) mengemukakan bahwa, aktivitas perikanan di Indonesia belum menunjukkan kinerja yang berkelanjutan. Permasalahan paling utama yang menjadi penyebabnya adalah sistem pengelolaan perikanan (fisheries management system) yang lemah, baik untuk perikanan tangkap maupun perikanan budidaya. Pengelolaan perikanan yang lemah, baik secara langsung maupun tidak langsung, tentunya akan menimbulkan ketidakteraturan dan tidak terkendalinya usaha perikanan nasional,yang pada akhirnya akan menyebabkan aktivitas perikanan nasional menjadi tidak berkelanjutan

Selanjutnya, Charles (2001) dalam paradigmanya tentang Sustainable Fisheries System, mengemukakan bahwa pembangunan perikanan yang berkelanjutan harus dapat mengakomodasi 4 aspek utama yang mencakup dari hulu hingga hilir, yakni:

1. Keberlanjutan ekologi (ecological sustainability): memelihara keberlanjutan stok/biomass sumber daya ikan sehingga pemanfaatannya 
tidak melewati daya dukungnya, serta meningkatkan kapasitas dan kualitas ekosistemnya.

2. Keberlanjutan (socioeconomic

sosio-ekonomi memperhatikan sustainability): keberlanjutan kesejahteraan para pelaku usaha perikanan dengan mempertahankan atau mencapai tingkat kesejahteraan masyarakat yang layak.

3. Keberlanjutan komunitas (community sustainability): menjaga keberlanjutan lingkungan komunitas atau masyarakat perikanan yang kondusif dan sinergis dengan menegakkan aturan atau kesepakatan bersama yang tegas dan efektif.

4. Keberlanjutan kelembagaan (institutional sustainability): menjaga keberlanjutan tata kelola yang baik, adil, dan bersih melalui kelembagaan yang efisien dan efektif guna mengintegrasikan atau memadukan tiga aspek utama lainnya (keberlanjutan ekologi, keberlanjutan sosio-ekonomi, dan keberlanjutan masyarakat)

Waduk Sempor merupakan salah satu waduk di Keb. Kebumen yang di manfaatkan masyarakat dalam bidang irigasi, perikanan, dan pariwisata. Waduk Sempor memiliki volume total air rata-rata 38 juta $\mathrm{m}^{3}$ dan luas genangan \pm 247 ha (Shaleh et al, 2014). Tidak berjalannya kelembagaan di Waduk Sempor mengakibatkan pemanfaatan di segala bidang belum maksimal bahkan bisa menimbulkan pengelolaan yang berdampak buruk pada lingkungan dan masyarakat setempat. Menurut Fauzi (2004) dalam Widiastuti (2015), adanya aktifitas subtractibility yang tinggi suatu tempat dikarenakan ketiadaan kelembagaan yang efektif atau kurang berfungsinya kelembagaan yang ada dalam mengatur alokasi sumber daya. Oleh karena itu identifikasi peran pemangku kepentingan (stake holder) di Waduk
Sempor perlu diketahui guna terciptanya pengelolaan sumber daya perairan yang berkelanjutan. Penelitian ini bertujuan untuk menganalisis pemangku kepentingan (stakeholder) dalam pengelolaan perairan di Waduk Sempor.

\section{METODE PENELITIAN}

Penelitian ini dilakukan di kawasan perairan Waduk Sempor, Kebumen, Jawa Tengah selama bulan Januari sampai April 2014. Kegiatan penelitian meliputi dua macam kegiatan yakni kegiatan di lapangan berupa pengambilan data primer dan sekunder. Data primer berupa variabel koordinasi, batas yuridiksi, property right dan aturan representasi diperoleh dengan menggunakan metode purposive sampling pada respoden. Responden kelembagaan berasal dari Kementrian Pekerjaan Umum (PU) Balai Besar Serayu Opak, Dinas Perikanan Kab. Kebumen, Kelompok Budidaya Ikan (Bina Marga Mulia),dan Kelompok Nelayan. Data sekunder merupakan data yang telah didokumentasikan yang berhubungan dengan penelitian yang diperoleh dari instansi terkait.

\section{Analisis Stakeholder}

Data primer meliputi variabel koordinasi, batas yuridiksi, property right dan aturan representasi terhadap pengelolaan perairan waduk. Data tersebut sudah termasuk didalamnya hak dan kewajiban, pengaturan izin usaha, tata ruang waduk, pengaturan kuantitas air, persepsi dan sistem pengorganisasian pengelolaan lingkungan waduk. Data dianalisis secara deskriptif dan diintepretsikan menggunakan metode logik. Metode logik adalah cara dimana data diamati dan dipilih-pilih, buktinya dicari dan dipertimbangkan/ dianalisis dan 
kesimpulan diambil ( Nazir, 1988 in Nasution, 2005).

\section{HASIL DAN PEMBAHASAN}

Waduk Sempor merupakan waduk yang memiliki berbagai pemanfaatan bagi masyarakat disekitar diantaranya perairan (irigasi), perikanan dan wisata. Pemangku kepentingan (stakeholder) di Waduk Sempor memiliki peran dalam pengelolaan yang ada sekitar waduk. Peran stakeholder dalam pengelolaan di Waduk Sempor terbagi menjadi tiga yaitu perikanan, PLTA dan Wisata. Pembagian peran dalam masing-masing stakeholder tercantum dalam tabel berikut ini.

Tabel. Peran pemangku kepentingan (stakeholder) di Waduk Sempor

\begin{tabular}{|c|c|c|c|c|c|c|c|}
\hline \multirow{2}{*}{ No } & \multirow{2}{*}{$\begin{array}{l}\text { Pemangku } \\
\text { Kepentingan }\end{array}$} & \multicolumn{3}{|c|}{ Kepentingan } & \multicolumn{3}{|c|}{ Pengaruh } \\
\hline & & Perikanan & PLTA & Wisata & Perikanan & PLTA & Wisata \\
\hline 1 & Petani KJA & 7 & & & 7 & & \\
\hline 2 & Kelompok KJA & 7 & & & 7 & & \\
\hline 3 & Dinas Perikanan & 3 & & & 5 & & \\
\hline 4 & BBWS Opak & 1 & 5 & & 1 & 5 & \\
\hline 5 & Dinas SDA ESDM & & 5 & & & 3 & \\
\hline 6 & Pengujung & & & 3 & & & 1 \\
\hline 7 & Pedagang & & & 3 & & & 5 \\
\hline & Kelompok Perahu & & & & & & \\
\hline 8 & Wisata & & & 7 & & & 5 \\
\hline 9 & Dinas Pariwisata & & & 3 & & & 1 \\
\hline 10 & Kelompok Nelayan & 7 & & & 7 & & \\
\hline
\end{tabular}

Pemangku

kepentingan

(stakeholder) di Waduk Sempor yang terlibat dalam pengembangan perikanan antara lain Balai BesarWilayah Sungai Serayu Opak (BBWSSO), Kelompok budidaya (Mina Marga Mulia dan Mina Giri Mukti), Kelompok nelayan (Mina Sari Asih dan Telaga Sari), Dinas Perikanan Kab Kebumen, pemancing dan pengepul.

$$
\text { Peran stakeholder dalam }
$$

pengelolaan perikanan sangat penting dan berpengaruh besar di Waduk Sempor yaitu Kelompok KJA, Kelompok Nelayan, Petani KJA dan Dinas Perikanan sedangkan peran BBWSO pada perikanan yaitu tidak penting dan tidak berpengaruh. Stakeholder yang sangat penting dan berpengaruh besar merupakan stake holder yang mampu mendorong perubahan dalam pengelolaan perikanan di Waduk Sempor. Oleh karena itu perlunya koordinasi antara stakeholder tersebut sehingga terciptanya peningkatan kesejahteraan masyarakat. 

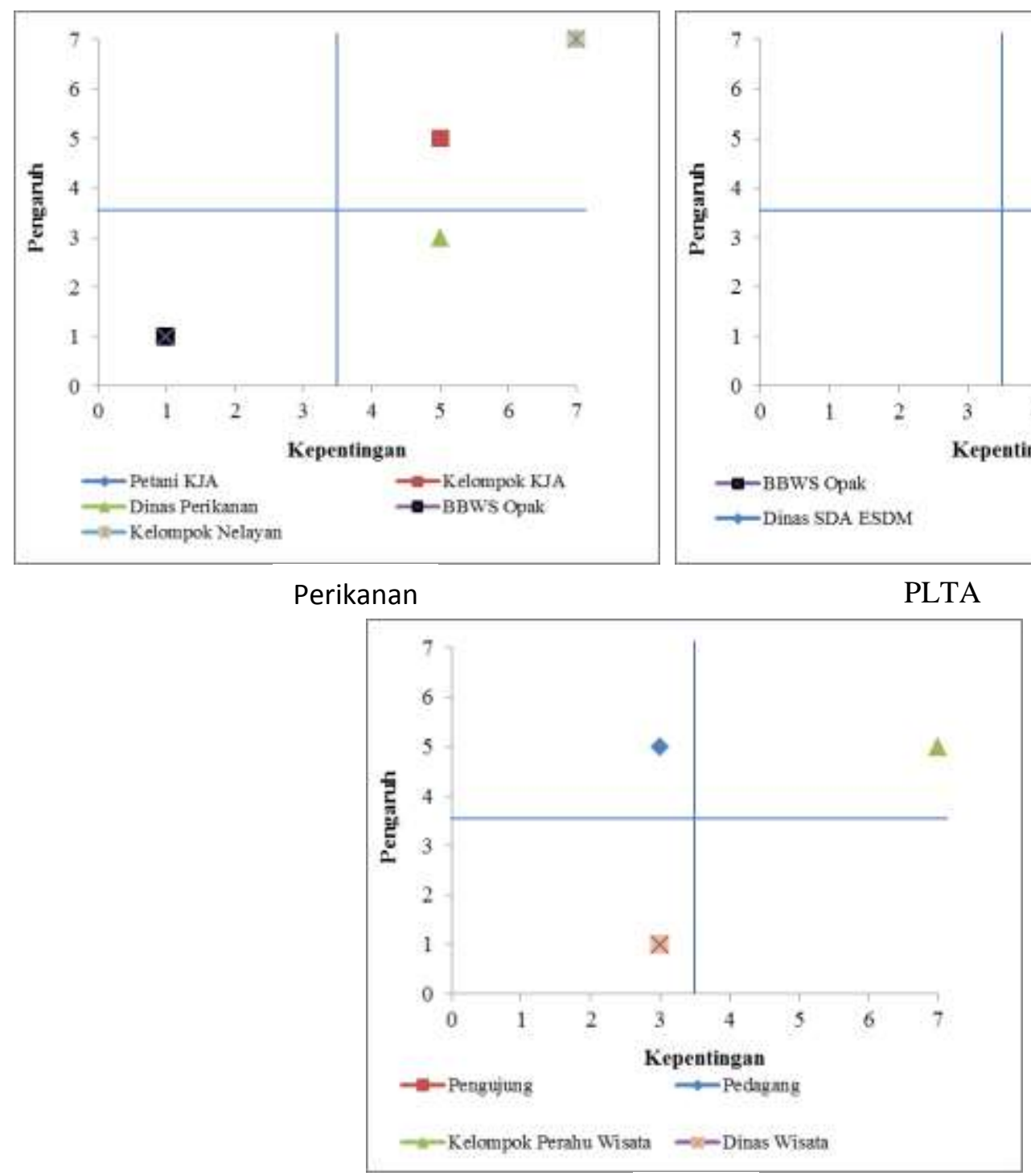

Wisata

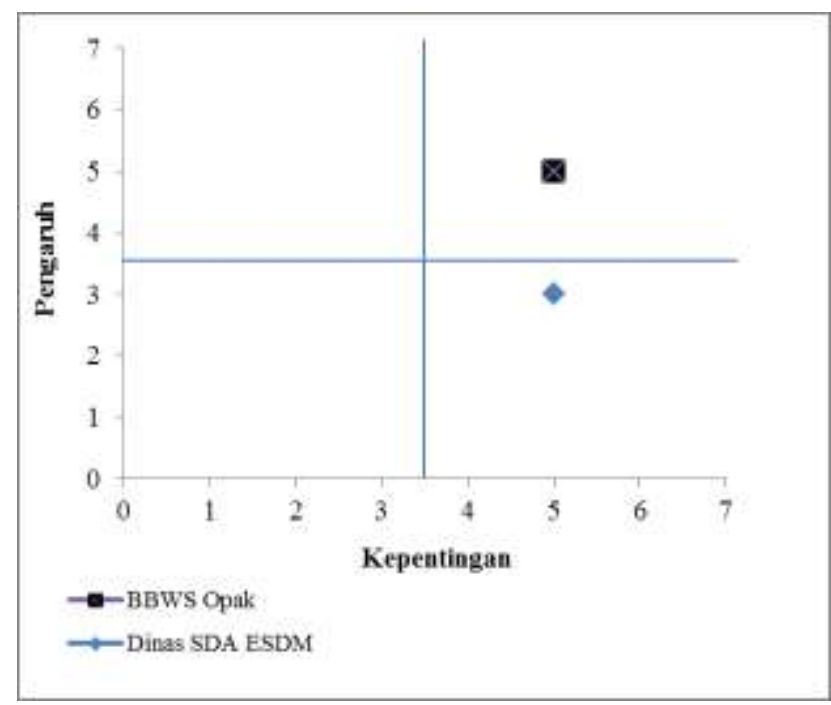

PLTA

Gambar. Analisis Stakeholder di Waduk Sempor

Kelembagaan di Waduk Sempor belum adanya fungsi pengaturan seperti pengaturan penangkapan ikan, pengaturan konservasi perairan, pengaturan pengawasan penangkapan ikan dan pengaturan pemasaran ikan. Kelembagaan di Waduk Malahayu Brebes telah melakukan fungsi pengaturan tersebut sehingga diharapkan produksi perairan umum waduk dapat berkelanjutan dan pemanfaatan serta pengelolaan sumberdaya perikanannya dapat berlangsung sesuai dengan prinsip pembangungan perikanan yang bertanggung jawab (Purnomo et al. 2009 in Nasution 2011).

Peran stakeholder dalam pengelolaan PLTA dan Irigasi yaitu BBWSO termasuk sangat penting dan berpengaruh besar sedangkan Dinas SDA ESDM termasuk cukup penting tetapi tidak berpengaruh. Hal ini dikarenakan kinerja pembangkit listrik dihasilkan berkisar 1,1 MegaWatt diatur sepenuhnya oleh BBWSO merupakan lembaga yang mengatur jumlah debit air serta valume air tampung yang berada di Waduk Sempor. 
Peran stakeholder dalam pengelolaan wisata antara lain Kelompok Perahu Wisata merupakan stakeholder yang sangat penting dan berpengaruh besar; Pedagang memiliki peran cukup penting tetapi berpengaruh sedangkan Dinas Wisata dan Pengunjung memiliki peran cukup penting tetapi tidak berpengaruh dalam pengelolaan. Potensi wisata di Waduk Sempor sangat potensial jika terjadi koordinasi dengan Kelompok Perahu Wisata serta pedagang dalam memberikan pelayanan pada pengujung. Dinas Wisata saat ini masih merupakan stake holder yang tidak berpengaruh dalam pengelolaan dikarenakan kurangnya inovasi-inovasi dalam program wisata yang mengundang datangnya para pengunjung.

Koordinasi bersama antar stakeholder dalam pengembangan di bidang perikanan, wisata, dan PLTA sangat diperlukan adanya kesepakatan bersama. Ada tiga aturan main utama dalam kelembagaan (Pakpahan 1991; Payne 1997) yaitu (1) Prinsip batas yurisdiksi (juridictional boundaries); (2) Hak kepemilikan (Property right); dan (3) Aturan keterwakilan (Rule of Representative). Jika kesepakatan ketiga aturan tersebut dapat diciptakan oleh semua stake holder di Waduk Sempor pengelolaan perairan akan terciptanya kesejahteraan masyrakat yang berkelanjutan .

\section{KESIMPULAN}

Pemangku kepentingan (Stakeholder) di Waduk Sempor terbagi dalam tiga bidang yaitu :

1. Perikanan

Kelompok Keramba Jaring Apung, Kelompok Nelayan serta Dinas Perikanan merupakan stakeholder yang sangat penting dan berpengaruh besar dalam pengelolaan perikanan.

2. PLTA dan Irigasi

Balai Besar Wilayah Sungai Serayu Opak merupakan stakeholder yang sangat penting dan berpengaruh besar dalam pengelolaan PLTA.

3. Wisata

Kelompok Perahu Wisata dan pedagang merupakan stakeholder yang sangat penting dan berpengaruh besar sedangkan Dinas Pariwisata tidak berpengaruh dalam pengelolaan Wisata.

\section{Saran}

Perlunya koordinasi dalam seluruh stakeholder dalam fungsi perikanan, PLTA, Wisata di Waduk Sempor membahas pengelolaan yang berdasarkan dengan daya dukung ekologi tetapi juga mendukung dalam peningkatan kesejahteraan masyarakat sekitar.

\section{DAFTAR PUSTAKA}

Kementrian PPN/Bapenas, 2014. Kajian Strategi Pengelolaan Perikanan Berkelanjutan. Direktorat Kelautan dan Perikanan

Charles, A. 2001. Sustainable Fishery Systems. Blackwell Science. Canada: 332pg

Shaleh F.R, Kadarwan S, Sigid H. 2014. Kualitas Air dan Status Kesuburan Perairan Waduk Sempor, Kebumen. JIPI. 19(3): 169-173. 
Widiastuti MMD. 2015. Analisis Kelembagaan Model AgentPrinciple Pada Petani Keramba Jaring Apung di Waduk Cirata Jawa Barat. Agricola. 5(2): 70-89

Nasution, Z. 2005. Analisis Kelembagaan dalam Pengelolaan Lingkungan Perairan Waduk (Studi Kasus di Perairan Waduk Jatiluhur, Jawa Barat. Buletin Ekonomi Perikanan Vol VI No. 1:Hal 1-11
Pakpahan, A. 1991. Perspektif Ekonomi Institusi dalam PengelolaanSumber dayaAlam. J Ekonomi dan Keuangan. 1.: 445464pp

Papyne, M. 1997. Modern Social Work Theory. Second Edition. London: McMillan Press, Ltd. 